\title{
Effects of the Selective Norepinephrine Reuptake Inhibitor Reboxetine on Norepinephrine and Serotonin Transmission in the Rat Hippocampus
}

\author{
Steven T. Szabo, B.Sc., and Pierre Blier, M.D., Ph.D.
}

Given that norepinephrine (NE) and serotonin (5-HT) neurons are implicated in the mechanisms of action of antidepressant drugs and both project to the hippocampus, the impact of acute and long-term administration of the selective NE inhibitor reboxetine was assessed on $\mathrm{CA}_{3}$ pyramidal neuron firing in this postsynaptic structure. Cumulative injections of reboxetine (1-4 mg/ $\mathrm{kg}$, i.v.) dosedependently increased the recovery time of the firing of these neurons following iontophoretic applications of NE, but not $5-H T$. In rats treated with reboxetine for $2.5 \mathrm{mg} / \mathrm{kg} /$ day for 21 days, a robust increase in the recovery time following $N E$ applications was observed, and a small but significant prolongation occurred following 5-HT applications. In controls and reboxetine-treated rats, 1 and $5 \mathrm{~Hz}$ stimulations of the afferent 5-HT bundle to the hippocampus, which allows determination of terminal 5-HT $\mathrm{T}_{1 \mathrm{~B}}$ autoreceptor sensitivity, produced similar frequency-dependent decreases in pyramidal neuron firing in both groups. However, after low and high doses of clonidine (10 and $400 \mu \mathrm{g} / \mathrm{kg}, i . v$.), which assesses $\alpha_{2-}$ adrenergic auto- and heteroreceptor sensitivity, respectively, only the effect of the high dose of clonidine was attenuated. Interestingly, administration of the selective $5-H T_{1 A}$ receptor antagonist WAY 100,635 induced a 140\% increase in basal pyramidal neuron firing in reboxetine as compared to saline-treated rats. This increase in tonic activation of postsynaptic $5-\mathrm{HT}_{1 A}$ receptors might be attributable in part to a desensitization of $\alpha_{2}$-adrenergic heteroreceptors, presumably resulting from sustained NE reuptake inhibition. These results indicate that even a selective NE reuptake inhibitor can modulate 5-HT transmission.

[Neuropsychopharmacology 25:845-857, 2001

(C) 2001 American College of Neuropsychopharmacology. Published by Elsevier Science Inc.
KEY WORDS: Antidepressants; $\alpha_{2}$-adrenoceptors; Clonidine; $5-H T_{1 A}$ receptors; $5-H T_{1 B}$ receptors; Locus coeruleus

From the Neurobiological Psychiatry Unit, McGill University, Montréal, Canada H3A 1A1(STS) and Department of Psychiatry, Brain Institute, University of Florida, Gainesville, Florida (PB).

Address correspondence to: Department of Psychiatry, Brain Institute, University of Florida, Gainesville, FL 32610-0256, Tel.: 352392-3681; Fax: 352-392-2579; E-mail: blier@psych.med.ufl.edu

Received February 12, 2001; revised April 24, 2001; accepted May 3, 2001.

Online publication: 5/7/01 at www.acnp.org/citations/Npp 05070117
The major classes of antidepressant drugs, including the tricyclic antidepressants (TCAs), monoamine oxidase inhibitors (MAOIs), and selective serotonin reuptake inhibitors (SSRIs), modify serotonin (5-HT) and/or norepinephrine (NE) neurotransmission through which they likely exert their therapeutic effects in anxiety and affective disorders (see Blier and de Montigny 1999). It has been postulated that antidepressant drugs selective for either the 5-HT or NE system act via independent mechanisms. Furthermore, these "selective" drugs display side effect profiles indicative of their neurotransmitter specificity. This, however, does not preclude that antidepressant agents specific for one monoaminergic 
transporter, or receptor subtype, may exert their therapeutic action through interactions between the 5-HT and NE systems. For example, SSRIs induce a gradual decrease in the spontaneous firing activity of NE neurons after long-term administration (Szabo et al. 1999, 2000), via a complex neuronal circuitry (Szabo and Blier 2000a), which may contribute to their beneficial and/or side effects depending on the symptomatic profile of the patients (Blier 2000). On the other hand, the selective NE reuptake inhibitor desipramine increases the synaptic availability of NE but also alters 5-HT parameters after long-term administration, such as enhancing extracellular 5-HT concentrations and the responsiveness of 5-HT receptors in postsynaptic structures (de Montigny and Aghajanian 1978; Wang and Aghajanian 1980; Menkes and Aghajanian 1981; Yoshioka et al. 1995). This enhanced synaptic availability of 5-HT may be due to a decreased sensitivity of $\alpha_{2}$-adrenergic heteroreceptors located on 5-HT terminals that normally induce a negative feedback regulation on 5-HT release (Mongeau et al. 1993; Yoshioka et al. 1995). Interestingly, all TCA drugs, independent of their capacity to inhibit the reuptake of 5-HT and/or NE, progressively enhance the responsiveness of postsynaptic $5-\mathrm{HT}_{1 \mathrm{~A}}$ receptors with a time-course congruent to the delayed onset of action of these drugs in major depression (de Montigny and Aghajanian 1978; Heninger et al. 1984; Chaput et al. 1991). Due to the lack of effective antidepressant drugs selective for the NE transporter not belonging to the TCA family, it has been difficult to assess whether the effects of desipramine on 5-HT transmission is attributable to its TCA moiety (because at least one of these drugs does not block NE reuptake) or to NE blockade per se.

Reboxetine is not a TCA and it is a selective NE reuptake inhibitor. It is currently the only antidepressant agent of its kind in clinical use in Europe. Given that $\mathrm{NE}$ and 5-HT monoaminergic brainstem nuclei project to the hippocampus, the impact of acute and long-term administration of reboxetine was assessed on $\mathrm{CA}_{3}$ pyramidal neuron firing in this brain region generally thought to be implicated in at least some aspects of depression. It is not currently known whether atrophy in the hippocampus represents a depressive state or trait (Sheline et al. 1999; Bremner et al. 2000), however antidepressant treatments have been shown to induce adaptive changes in this structure (see Malberg et al. 2000 for review). The effect of reboxetine on NE transmission in this manuscript was not directly assessed as Sacchetti et al. (1999) already concluded that acute and sustained treatment with reboxetine leads to similar increases in extracellular levels of NE without producing any adaptive changes in $\alpha_{2}$-autoreceptor sensitivity in the hippocampus. However, given the importance of receptors on 5-HT terminals in the hippocampus, which become altered after long-term antidepressant treat- ment, $\alpha$-adrenergic heteroreceptor and $5-\mathrm{HT}_{1 \mathrm{~B}}$ autoreceptor function was assessed using electrical stimulation of the afferent 5-HT bundle to this postsynaptic structure.

\section{MATERIALS AND METHODS}

\section{Animals and Treatments}

The experiments were carried out in male Sprague Dawley rats (Charles River, St. Constant, Québec, Canada) weighing 300-325 g and were kept under standard laboratory conditions (12:12 light-dark cycle with access to food and water ad libitum, at a room temperature of $\left.21 \pm 2^{\circ} \mathrm{C}\right)$. Rats were anesthetized with chloral hydrate $(400 \mathrm{mg} / \mathrm{kg}$, i.p.) and mounted in a stereotaxic apparatus (David Kopf Instruments). Supplemental doses (100 mg/ kg, i.p.) were given to prevent any nociceptive reaction to pinching of the hind paw. Body temperature was maintained at $37^{\circ} \mathrm{C}$ throughout the experiments utilizing a thermistor-controlled heating pad (Seabrook Medical Instruments, Inc.). Prior to electrophysiological recording, a catheter was inserted in a lateral tail vein for systemic i.v. injection of drugs. All experiments were performed in compliance with $\mathrm{NIH}$ guidelines and the Canadian Council on Animal Care.

In sustained treatment regimens, rats were anesthetized with halothane containing a $2: 1 \mathrm{O}_{2} / \mathrm{N}_{2} \mathrm{O}$ mixture for subcutaneous implantation of osmotic Alzet 2ML4 minipumps (ALZA, Palo Alto, CA). The rats were tested with the minipumps in place in order to mimic the clinical condition whereby patients present an antidepressant response while taking their medication. Rats were treated with reboxetine $(2.5 \mathrm{mg} / \mathrm{kg} /$ day $)$ or the saline vehicle for 21 days delivered by osmotic minipumps. This dose was chosen because it produced a similar degree of attenuation of LC neuronal firing after a two-day treatment to that obtained with regimens of desipramine and MAOIs examined in long-term studies (Szabo and Blier 2001; Blier and de Montigny 1985).

\section{Recording from Dorsal Hippocampus $\mathrm{CA}_{3}$ Pyramidal Neurons}

Extracellular unitary recordings and microiontophoresis of drugs onto pyramidal neurons in the $\mathrm{CA}_{3}$ region of the dorsal hippocampus were conducted with fivebarreled micropipettes, pulled conventionally with the tips broken to a diameter of 9 to $12 \mu \mathrm{m}$ under a microscopic control. The central barrel, used for recording, was filled with a $2 \mathrm{M} \mathrm{NaCl}$ solution. The side barrels contained the following solutions: 5-HT creatinine sulfate $(5 \mathrm{mM}$ in $200 \mathrm{mM} \mathrm{NaCl}, \mathrm{pH} 4), \mathrm{NE}$ bitartrate (20 $\mathrm{mM}$ in $200 \mathrm{mM} \mathrm{NaCl}, \mathrm{pH} 4)$, quisqualate $(1.5 \mathrm{mM}$ in 200 $\mathrm{mM} \mathrm{NaCl}, \mathrm{pH} 8$ ), and a $2 \mathrm{M} \mathrm{NaCl}$ solution used for automatic current balancing. All drug solutions were in- 
jected as cations and retained with a -10 nA current between injections. Pyramidal neurons were identified by their large amplitude $(0.5 \mathrm{mV}$ to $1.2 \mathrm{mV})$ and longduration (0.8 msec to $1.2 \mathrm{msec}$ ) simple spike alternating with complex spike discharges (Kandel and Spencer 1961). These characteristics readily allow the on-line differentiation of pyramidal neurons from interneurons. Since most hippocampus pyramidal neurons are not spontaneously active under chloral hydrate anesthesia, small ejection currents of quisqualate ( 0 to $5 \mathrm{nA}$ ) were used to activate them within their physiological firing rate 8-15 Hz; (Ranck 1975). Furthermore, the level of cellular activation of the pyramidal neurons does not alter the estimates of neuronal responsiveness (Brunel and de Montigny 1987). To evaluate the effectiveness of reboxetine on the blockade of NE and 5-HT transporter reuptake, the recovery of the firing activity of pyramidal neurons following the microiontophoretic application of NE and 5-HT was assessed using the recovery time $50\left(\mathrm{RT}_{50}\right)$ value. The $\mathrm{RT}_{50}$ value is defined as the time in seconds required by the neurons to recover $50 \%$ of the initial firing frequency from termination of microiontophoretic application (de Montigny et al. 1980). The $\mathrm{RT}_{50}$ value has also been shown to be a reproducible measure and a reliable index of the in vivo activity of the 5-HT and NE reuptake process which is independent from postsynaptic neuronal responsiveness (de Montigny et al. 1980; Piñeyro et al. 1994). The neuronal responsiveness to microiontophoretic applications of $\mathrm{NE}$ and 5-HT was assessed and expressed as the number of spikes suppressed. This approach avoids an interference of the recovery of firing which is largely dependent on the activity of the reuptake transporters (Chaput et al. 1986). The sensitivity of neurons to NE or 5-HT was evaluated by counting the number of spikes suppressed during drug ejections.

\section{Simulation of the 5-HT pathway}

To activate the 5-HT projections originating from the dorsal and median raphe to the dorsal hippocampus (Hensler et al. 1994), a bipolar electrode (NE-100; David Kopf, Tujunga, CA) was implanted on the midline with a $10^{\circ}$ backward angle in the ventromedial tegmentum, 1 $\mathrm{mm}$ anterior to lambda, and $8.3 \mathrm{~mm}$ below the cortical surface. A stimulator (S8800; Grass Instrument, Quincy, Mass; USA) delivered 200 square pulses of $0.5 \mathrm{~ms}$ at a frequency of 1 or $5 \mathrm{~Hz}$ at an intensity of $300 \mu \mathrm{A}$. The duration of suppression of pyramidal neurons firing activity produced by stimulation was measured on-line using an oscilloscope with memory (1201B; Hewlett Packard; Palo Alto, CA). The effect of the electrical stimulation of the ascending 5-HT pathway is due to the release of 5-HT into the synaptic cleft (Blier and de Montigny 1983, 1985; Chaput et al. 1986). In order to determine the function of the terminal 5-HT autorecep- tors, two series of stimulations $(1$ and $5 \mathrm{~Hz})$ were carried out, while recording the same neurons. Since it has been previously demonstrated that the activation of the terminal 5-HT autoreceptors decreases the release of $5-\mathrm{HT}$, thus increasing the frequency of stimulation from 1 to $5 \mathrm{~Hz}$ results in a greater activation of terminal 5-HT autoreceptors (Blier et al. 1989; Göthert and Huth 1980). Also, the effect of $1 \mathrm{~Hz}$ stimulations was determined while recording from the same neurons before and after the successive intravenous injection of a low dose (10 $\mu \mathrm{g} / \mathrm{kg})$ and high dose $(400 \mu \mathrm{g} / \mathrm{kg})$ of clonidine. The effects of the electrical stimulation on $\mathrm{CA}_{3}$ pyramidal neuron firing rate following low and high doses of clonidine allows for the assessment of the sensitivity of $\alpha_{2}$-adrenergic auto- and heteroreceptors, respectively (Mongeau et al. 1994a). This is supported by previous experiments showing that in rats pretreated with the NE neurotoxin 6-hydroxydopamine, the inhibitory effects of the high dose of clonidine was abolished, but the enhancing action of the low dose did not change (Mongeau et al. 1993). Furthermore, prolonged treatment with the monoamine oxidase inhibitor befloxatone selectively attenuates the effect of the high dose of clonidine in intact rats but not in NE-lesion rats (Mongeau et al. 1994a).

\section{Tonic Activation of 5-HT $\mathrm{HA}_{1 \mathrm{~A}}$ Receptors on Dorsal Hippocampus $\mathrm{CA}_{3}$ Pyramidal Neurons}

The selective 5- $\mathrm{HT}_{1 \mathrm{~A}}$ receptor antagonist WAY 100,635 (Fletcher et al. 1996) was used to assess the degree of $5-\mathrm{HT}_{1 \mathrm{~A}}$ receptor-mediated inhibition of $\mathrm{CA}_{3}$ pyramidal neurons induced by the sustained administration of reboxetine for 21 days. The degree to which the antagonists could disinhibit the firing of hippocampal neurons has been determined to be a measure of the tonic activation of postsynaptic $5-\mathrm{HT}_{1 \mathrm{~A}}$ receptors (Haddjeri et al. 1998). In reboxetine-treated rats, if an increase in extracellular levels of 5-HT in the raphe region were present, WAY 100,635 would restore 5-HT neuron firing activity. However, this is probably not the case as it was previously documented that the firing activity of dorsal raphe 5 -HT neurons, and the responsiveness of 5- $\mathrm{HT}_{1 \mathrm{~A}}$ autoreceptors controlling these neurons, is not altered after a prolonged reboxetine administration (Szabo and Blier 2001). Nevertheless, because WAY 100,635 was given systemically, it would simultaneously be blocking the effects of 5-HT on postsynaptic neurons, thereby canceling out the effect of WAY 100,635 on the somatondendritic autoreceptors. Indeed, if the action of the antagonist at the somatodendritic $5-\mathrm{HT}_{1 \mathrm{~A}}$ autoreceptors were influencing the activity of hippocampus neurons, it would serve to further inhibit their firing rate due to an increased release of 5-HT into the target area. Therefore, it was assumed that any increases in firing observed during the administration of WAY 100,635 
would be a reflection of the action of the antagonist at postsynaptic $5-\mathrm{HT}_{1 \mathrm{~A}}$ receptors. Thus, given that WAY 100,635 antagonizes the action of exogenous 5-HT at postsynaptic $5-\mathrm{HT}_{1 \mathrm{~A}}$ receptors, $\mathrm{CA}_{3}$ pyramidal neuron activity would be a direct measure of the tonic level of activation of these receptors by extracellular 5-HT. Prior to the intravenous administration of four successive $25-\mu \mathrm{g} /$ $\mathrm{kg}$ doses of WAY 100,635, the firing activity of the quisqualate-activated $\mathrm{CA}_{3}$ pyramidal neurons was decreased to about $5 \mathrm{~Hz}$ in order to more readily allow the detection of enhancements in firing following administration of the antagonist in control and treated rats. After a steady baseline firing activity was established, an injection of saline always preceded the WAY 100,635 injections.

\section{Drugs}

The following drugs were used: reboxetine (Pharmacia \& UpJohn, Kalamazoo, MI, USA); clonidine and WAY 100,635 (RBI, Natick, MA, U. S. A.); 5-HT creatinine sulfate, NE bitartrate, and quisqualate were purchased from Sigma Chemical (St. Louis, MO, USA). The concentrations and the doses used for these compounds were chosen on the basis of previous successful experiments carried out in our laboratory and others. Drugs administered i.v. were all dissolved in distilled water and injected in a volume of less than $0.2 \mathrm{ml}$.

\section{Statistical Analysis}

Results were expressed as means \pm SEM. The $n$ refers to the number of neurons tested in the figures, however, in the results section $\mathrm{n}$ corresponds to the number of rats tested. The statistical significant difference between the means of iontophoretic application of NE and $5-\mathrm{HT}$ on $\mathrm{CA}_{3}$ pyramidal neurons firing activity to intravenous reboxetine injections and long-term reboxetine administration of $\mathrm{RT}_{50}$ values as well as the number of spikes suppressed was assessed with 2-way analysis of variance (ANOVA). The difference between the effects of 1 and $5 \mathrm{~Hz}$ stimulation frequencies of the 5-HT pathway on the duration of suppression of firing of $\mathrm{CA}_{3}$ pyramidal neurons was assessed with the paired Student's $t$-test. Possible differences in the magnitude of the effects of $1 \mathrm{~Hz}$ electrical stimulation frequencies of the 5-HT pathway to intravenous clonidine injections in control and 21-day reboxetine-treated rats were assessed via 1-way ANOVA. Lastly, the effects of cumulative injections of reboxetine in control rats, and incremental doses of WAY 100,635 injections on the firing activity of $\mathrm{CA}_{3}$ pyramidal neurons in control and 21day reboxetine-treated rats were assessed using the 1way repeated measures ANOVA. Post-hoc pairwise multiple comparison procedures were performed with the Tukey test and the Student-Newman-Keuls method for 1-way and 2-way ANOVAs, respectively.

\section{RESULTS}

\section{Effects of Acute Reboxetine Injections on the Response of $\mathrm{CA}_{3}$ Pyramidal Neurons to Microiontophoretic Applications of NE and 5-HT}

The average number of spikes suppressed from baseline firing activity of hippocampus neurons during microiontophoretic applications of NE and 5-HT provides a reliable index of the sensitivity of postsynaptic $\alpha_{2}$-adrenergic and $5-\mathrm{HT}_{1 \mathrm{~A}}$ receptors, respectively (Curet and de Montigny 1988a; Rueter et al. 1998). These values generated from microiontophoretic applications of $\mathrm{NE}$ and 5-HT on the firing activity of $\mathrm{CA}_{3}$ pyramidal neurons was significant $\left(\mathrm{F}_{2,122}=15.4\right.$ and $\mathrm{F}_{2,120}=11.3$, respectively; $p<.001$ for both monoamines) and currentdependent ( $p<.05$ for both monoamines), meaning that increasing ejection currents enhanced the number of spikes suppressed following NE and 5-HT ejections from the micropipette, examples of which are provided in Figure 1. The recovery time necessary for pyramidal neurons to regain $50 \%$ of their firing rate $\left(\mathrm{RT}_{50}\right.$ value) after microiontophoretic ejections of NE and 5-HT provides an index of the function of the reuptake transporters for these monoamines (de Montigny et al. 1980; Piñeyro et al. 1994). The $\mathrm{RT}_{50}$ values generated from microiontophoretic applications of NE and 5-HT on the firing activity of $\mathrm{CA}_{3}$ pyramidal neurons were significantly prolonged $\left(\mathrm{F}_{2,122}=35.0\right.$ and $\mathrm{F}_{2,120}=27.1$, respectively; $p<.001$ for both monoamines) and also currentdependent ( $p<.05$ for both monoamines), examples of which are also provided in Figure 1.

Cumulative doses of 1,2 and $4 \mathrm{mg} / \mathrm{kg}$ of reboxetine were i.v. injected in succession and reduced the firing activity of $\mathrm{CA}_{3}$ pyramidal neurons to $15 \%, 13 \%$, and $23 \%$, respectively, but did not significantly differ from baseline or each other $\left(\mathrm{F}_{3,12}=1.6, p=.248 ; \mathrm{n}=4\right.$ rats $)$, similar to desipramine (Curet et al. 1992). Reboxetine injections did not significantly influence the number of spikes suppressed by microiontophoretic applications of NE $\left(\mathrm{F}_{3,121}=0.1, p=1.0\right)$ and 5-HT $\left(\mathrm{F}_{3,119}=0.3, p=\right.$ .8). There was no statistically significant interaction between the different doses of reboxetine injected and current of NE and 5-HT ejected on the number of spikes suppressed $\left(\mathrm{F}_{6,118}=0.1, p=.990\right.$ and $\mathrm{F}_{6,116}=0.4, p=$ .87 , respectively). In contrast, 1,2 , and $4 \mathrm{mg} / \mathrm{kg}$ injections of reboxetine prolonged the $\mathrm{RT}_{50}$ values across all of the currents employed on $\mathrm{CA}_{3}$ pyramidal neurons firing for NE current ejections as compared to controls $\left(\mathrm{F}_{3,122}=58.4, p<.001\right.$; Figure 2$)$, but not to that of 5-HT $\left(\mathrm{F}_{3,119} 1.7, p=.176\right.$; Figure 2$)$. The effect of reboxetine on this parameter of NE was dose dependent and reached a plateau at the cumulative dose of $2 \mathrm{mg} / \mathrm{kg}(p<.05$; 

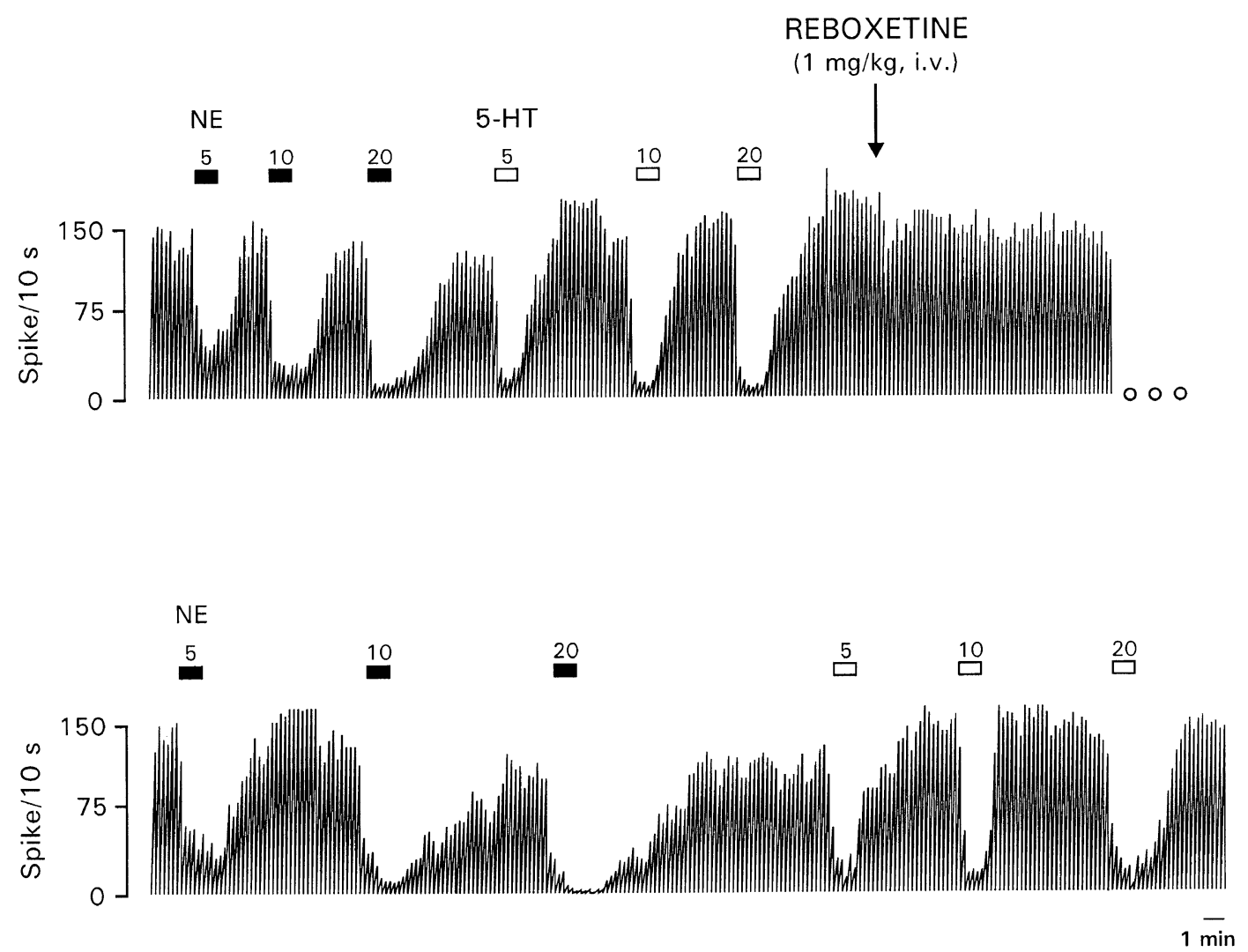

Figure 1. Integrated firing rate histograms illustrating the response of a $\mathrm{CA}_{3}$ pyramidal neuron to microiontophoretic application of NE and 5-HT in a control rat before and after a reboxetine injection. The three circles at the bottom of the upper histogram indicate that it continues below. This neuron was activated with a quisqualate ejection current of $-3 \mathrm{nA}$. Note that when compared to microiontophoretic drug application before reboxetine injection, the durations of $\mathrm{CA}_{3}$ pyramidal neuron suppression with applications of NE are markedly increased and those for 5-HT are unchanged.

Figure 3). Importantly, the lack of effect observed for 5-HT across reboxetine injections was unrelated to the current used $\left(\mathrm{F}_{6,116}=0.2, p=.97\right)$.

\section{Effect of 21-day Reboxetine Administration on the Response of $\mathrm{CA}_{3}$ Pyramidal Neurons to Microiontophoretic Applications of NE and 5-HT}

In reboxetine-treated rats, a significant number of spikes were suppressed for microiontophoretic application of NE and 5-HT $\left(\mathrm{F}_{2,98}=22.8\right.$ and $\mathrm{F}_{2,109}=9.1$, respectively; $p<.001$ for both monoamines) on $\mathrm{CA}_{3}$ pyramidal neurons. The effect of NE and 5-HT ejections on the number of spikes suppressed was current-dependent ( $p<.05$ for both monoamines); however, it did not differ among controls and treated rats $\left(\mathrm{F}_{1,99}=3.2, p=.08\right.$ and $\mathrm{F}_{1,110}=0.4, p=.55$, respectively; Figure 4). This lack of difference observed in reboxetine-treated rats as compared to controls on the number of spikes suppressed from NE and 5-HT current ejections were not due to the effects of reboxetine treatment $\left(\mathrm{F}_{2,98}=0.5, p=\right.$ .95 and $\mathrm{F}_{2,109}=0.9 p=.41$, respectively). Similarly, the $\mathrm{RT}_{50}$ value for NE and 5-HT applications on $\mathrm{CA}_{3}$ neu- rons in reboxetine-treated rats also increased in a current-dependent manner ( $p<0.05$ for both monoamines; Figure 5, Panel A and Panel B, respectively). In contrast to the number of spikes suppressed obtained for 5-HT ejections, where no difference was detected regardless of drug treatment, an enhancement resulted in the $\mathrm{RT}_{50}$ values to microiontophoretic applications of $\mathrm{NE}$ and $5-\mathrm{HT}$ in reboxetine-treated rats on the firing activity of $\mathrm{CA}_{3}$ neurons as compared to controls $\left(\mathrm{F}_{2,152}=79.7\right.$ and $\mathrm{F}_{2,158}=58.7$, respectively, $p=.001$ for both monoamines). Furthermore, this difference was also present in the subset of neurons for which all currents were used: the $\mathrm{RT}_{50}$ values for NE and 5-HT were almost exactly the same and still significantly different from the control values $\left(\mathrm{F}_{2,152}=35.8\right.$ and $\mathrm{F}_{2,92}=19.4$, respectively, $p<$ $.001)$. This prolongation of the effect of 5-HT ejections, as indicated by an enhanced $\mathrm{RT}_{50}$ value on $\mathrm{CA}_{3}$ neuron firing, was much less robust than that observed for NE (Figure 5, Panels A and B), but was nevertheless statistically significant $\left(\mathrm{F}_{1,159}=46.8, p<.001\right)$. In addition, this effect of NE or 5-HT on the $\mathrm{RT}_{50}$ value did not depend on the current used $\left(\mathrm{F}_{2,152}=2.6, p=.79\right.$ and $\mathrm{F}_{2,159}=0.5, p$ $=.59$, respectively). 


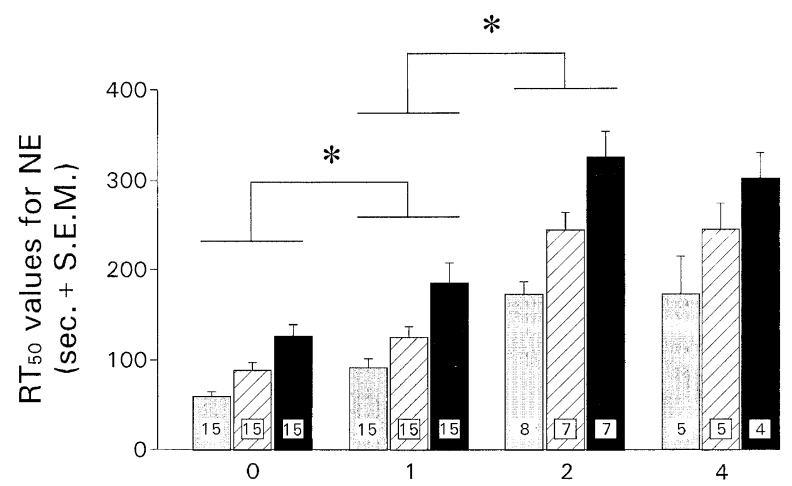

$5 \mathrm{nA} \mathrm{NE}$ $10 \mathrm{NANE}$ $20 \mathrm{nA} N \mathrm{NE}$

Reboxetine (mg/kg, i.v.)

Figure 2. Histograms representing the recovery times $\left(\mathrm{RT}_{50}\right)$ of dorsal hippocampus $\mathrm{CA}_{3}$ pyramidal neurons from microiontophoretic applications of NE with varying currents in control rats receiving cumulative i.v. injections of reboxetine. The number of neurons tested is given at the bottom of each column. ${ }^{*} p<.001$ when comparing microiontophoretic NE applications using 2-way ANOVA with Student-Newman-Keuls method.

\section{Effect of Long-Term Reboxetine Treatment on the Effectiveness of Electrical Stimulation of the Afferent 5-HT Fibers to the Hippocampus}

The net effect of long-term reboxetine treatment on 5-HT transmission was determined by stimulating the ascending 5-HT pathway at a frequency $(1 \mathrm{~Hz})$ similar to the spontaneous firing rate of 5-HT neurons (Vandermaelen and Aghajanian 1983). A brief suppression of firing of $\mathrm{CA}_{3}$ neurons results from electrical stimulation of the 5-HT pathway due to the release of 5-HT mediated through postsynaptic $5-\mathrm{HT}_{1 \mathrm{~A}}$ receptors (Chaput et al. 1986; Chaput and de Montigny 1988). The effectiveness of the electrical stimulation of the ascending 5-HT fibers at the level of the ventromedial tegmentum on the firing activity of the postsynaptic hippocampal $\mathrm{CA}_{3}$ pyramidal neurons at a frequency of $1 \mathrm{~Hz}$ did not differ $(p=.74)$ in control and reboxetine-treated rats (Figure 6). To assess the function of the terminal 5- $\mathrm{HT}_{1 \mathrm{~B}}$ autoreceptors which control the amount of 5-HT released for each electrical impulse reaching 5-HT terminals, the ascending 5-HT pathway was subsequently stimulated at a frequency of $5 \mathrm{~Hz}$ while recording the firing activity of the same hippocampus $\mathrm{CA}_{3}$ pyramidal neurons. In controls and reboxetine-treated rats, increasing the frequency of stimulation from 1 to $5 \mathrm{~Hz}$ induced the same $26 \%$ reduction of the duration of suppression of firing $\left(t_{17}=11.87\right.$ and $t_{9}=13.95$, respectively, $p<.001$ for both groups; Figure 6). Thus, at a frequency of $5 \mathrm{~Hz}$, the effectiveness of the electrical stimulations in reboxetinetreated rats was not different from that of the controls $(p=.42$; Figure 6$)$.

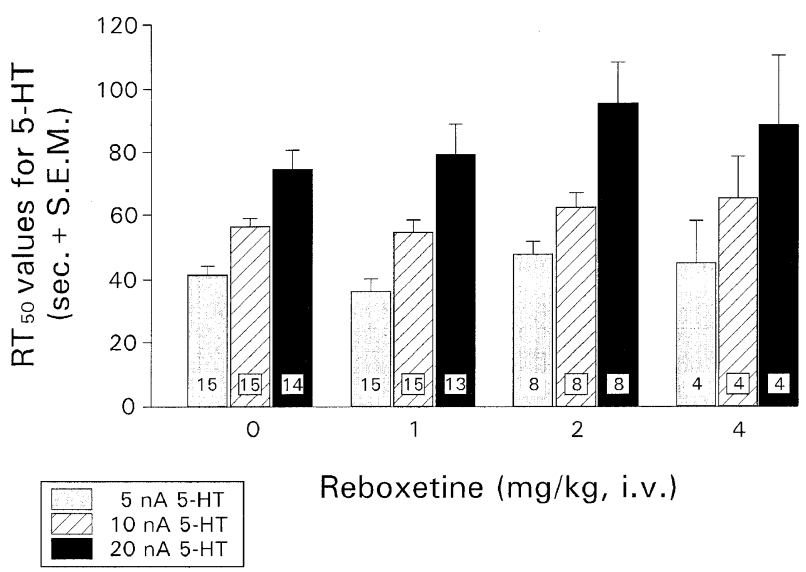

Figure 3. Histograms representing recovery time $\left(\mathrm{RT}_{50}\right)$ of dorsal hippocampus $\mathrm{CA}_{3}$ pyramidal neurons from microiontophoretic applications of 5-HT with varying currents in control rats receiving cumulative injections of reboxetine. The number of neurons tested is given at the bottom of each column. Note that reboxetine administration did not alter the current-dependent increases in the $\mathrm{RT}_{50}$ value as opposed to that for NE illustrated in Figure 2.

\section{Effects of Long-Term Treatment with Reboxetine on the Sensitivity of $\alpha_{2}$-Adrenergic Auto- and Heteroreceptors}

Previous studies have shown that antidepressant treatments which increase the concentration of NE in the synaptic cleft desensitize the terminal $\alpha_{2}$-adrenergic heteroreceptors located on 5-HT fibers in the dorsal hippocampus after long-term administration (Mongeau et al. 1994a,b; Yoshioka et al. 1995), however, leaving $\alpha_{2}$-adrenergic autoreceptors normosensitive (Szabo and Blier 2001; Sacchetti et al. 1999; Mateo et al. 1998; Mongeau et al. 1994a; Moret and Briley 1994). In control ( $\mathrm{n}=$ 9 rats) and 21-day reboxetine $(2.5 \mathrm{mg} / \mathrm{kg} /$ day; $\mathrm{n}=7)$ treated rats, $1 \mathrm{~Hz}$ electrical stimulations of the ascending 5-HT pathway on the firing activity of dorsal hippocampus $\mathrm{CA}_{3}$ pyramidal neurons produced similar suppressions of firing which did not statistically differ when compared to each other ( $p=.27$; Figure 7). In addition, a low dose of clonidine $(10 \mu \mathrm{g} / \mathrm{kg})$, which accesses the sensitivity of terminal $\alpha_{2}$-adrenergic autoreceptors, was able to significantly increase the effectiveness of a $1 \mathrm{~Hz}$ stimulation to a similar degree in control $(34 \%)$ and reboxetine-treated $(30 \%)$ rats $(p<$ .001 for both; Figure 7). In contrast, a high dose of clonidine $(400 \mu \mathrm{g} / \mathrm{kg})$, which assesses the sensitivity of terminal $\alpha_{2}$-adrenergic heteroreceptors, significantly reduced the effectiveness of $1 \mathrm{~Hz}$ electrical stimulations as compared to the stimulations without clonidine injection in controls $(25 \%)$, but not in 21-day reboxetine-treated rats $(p<.001$ and $p=.79$, respectively; Figure 7). 
A. NE

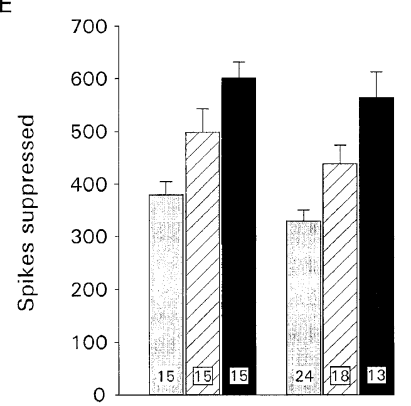

B. $5-\mathrm{HT}$

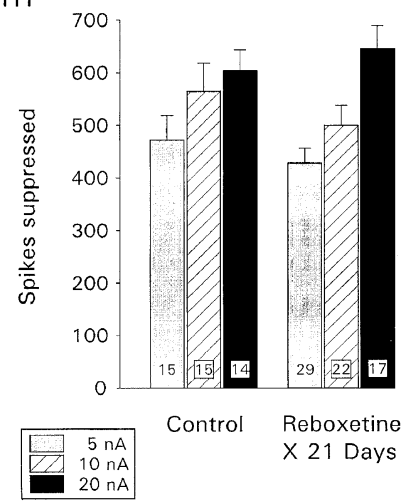

Figure 4. Histograms representing the number of spikes suppressed of dorsal hippocampus $\mathrm{CA}_{3}$ pyramidal neurons from microiontophoretic applications of NE (Panel A) and 5-HT (Panel B) with varying currents in control and 21-day reboxetine $(2.5 \mathrm{mg} / \mathrm{kg} /$ day $)$ treated rats. The number of neurons tested is given at the bottom of each column. All of the currents differed from each other on the number of spikes suppressed ( $p<.05$ ); however, they did not differ when compared across treatment groups using the 2-way ANOVA with Student-Newman-Keuls method.

\section{Effect of Long-Term Treatment with Reboxetine on the Tonic Activation of $5-\mathrm{HT}_{1 \mathrm{~A}}$ Receptors Using WAY 100,635}

Due to a recent finding that all major classes of antidepressants induce a tonic activation of postsynaptic $5-\mathrm{HT}_{1 \mathrm{~A}}$ receptors in the hippocampus (Haddjeri et al. 1998), the possibility that reboxetine could also influence this parameter was examined. Dorsal hippocampus $\mathrm{CA}_{3}$ pyramidal neurons were activated by applying a small ejection current of quisqualate in controls and long-term reboxetine-treated rats ( $\mathrm{n}=5$ rats for both groups); an example of each is provided in Figure 8. In control rats receiving saline for 21 days, the i.v. administration of the selective $5-\mathrm{HT}_{1 \mathrm{~A}}$ receptor antagonist WAY 100,635 (four successive doses of $25 \mu \mathrm{g} / \mathrm{kg}$ ) did not modify the firing activity of dorsal hippocampus $\mathrm{CA}_{3}$ pyramidal neurons ( $p=.08$; Figure 8, Panel A). In contrast to rats receiving reboxetine for 21 days, i.v. administration of the second dose and subsequent doses of WAY 100,635 was able to induce a marked enhancement of the firing activity of $\mathrm{CA}_{3}$ pyramidal neurons $(p<.001$ for all doses
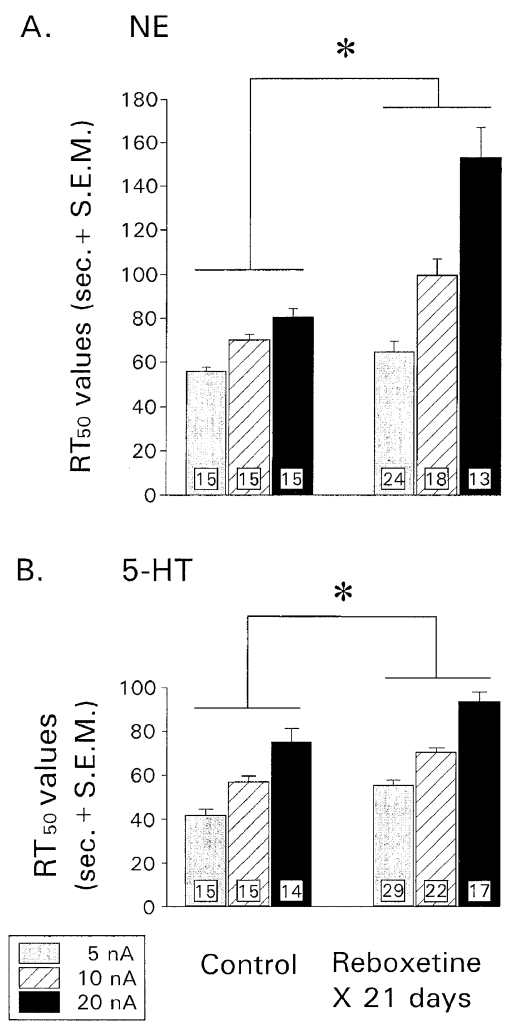

Figure 5. Histograms representing recovery times $\left(\mathrm{RT}_{50}\right)$ of dorsal hippocampus $\mathrm{CA}_{3}$ pyramidal neurons from microiontophoretic applications of NE (Panel A) and 5-HT (Panel B) with varying currents in control and 21-day reboxetine $(2.5 \mathrm{mg} / \mathrm{kg} /$ day) treated rats. The number of neurons tested is given at the bottom of each column. ${ }^{*} p<.001$ using 2-way ANOVA with Student-Newman-Keuls method.

except the first; Figure 8, Panel B and Figure 9). The effect of a final injection of WAY 100,635 (cumulative dose of $100 \mu \mathrm{g} / \mathrm{kg}$ ) increased the firing activity of $\mathrm{CA}_{3}$ pyramidal neurons by $140 \%$ above the basal firing rates (Figure 9).

\section{DISCUSSION}

The electrophysiological results presented herein indicate that acute injections of reboxetine prolonged the duration of NE in the hippocampus via blockade of the $\mathrm{NE}$ transporter, as measured by a greater $\mathrm{RT}_{50}$ value for $\mathrm{NE}$ applications onto $\mathrm{CA}_{3}$ pyramidal neurons (Figures 1 and 2). In contrast, reboxetine injections did not alter this parameter for 5-HT applications on the same neurons, demonstrating that acute injections of reboxetine do not impact upon the function of the 5-HT transporter in this postsynaptic structure when the effect of $\mathrm{NE}$ is prolonged more than 2-fold (Figures 1 and 3). This specific effect of reboxetine on the $\mathrm{RT}_{50}$ values to application of $\mathrm{NE}$ and 5-HT on $\mathrm{CA}_{3}$ pyramidal neuron firing is similar to results obtained with the TCA de- 


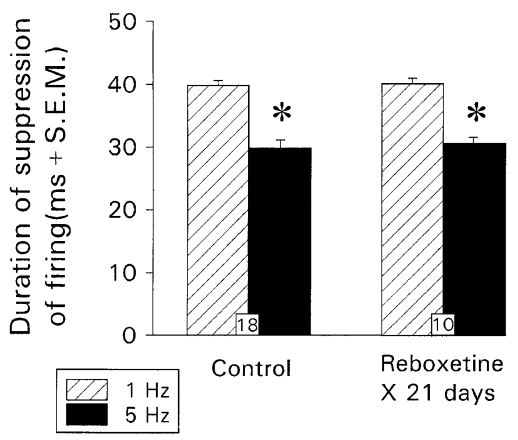

Figure 6. Effects of 1 and $5 \mathrm{~Hz}$ electrical stimulations of the ascending 5-HT pathway in suppressing the firing activity of dorsal hippocampus $\mathrm{CA}_{3}$ pyramidal neurons in 9 control and 8 reboxetine $(2.5 \mathrm{mg} / \mathrm{kg} /$ day $\times 21$ days $)$ treated rats. ${ }^{*} p<$ .001 using the paired Student's t test.

sipramine (Lacroix et al. 1991). These findings are also consistent with the results of microdialysis studies showing that acute reboxetine administration $(15 \mathrm{mg} /$ $\mathrm{kg}$, i.p.) produces an increased level of NE in the dialysates in the frontal cortex and dorsal hippocampus without altering that of 5-HT in the striatum (Sacchetti et al. 1999). When considered together with biochemical binding data on the transporter (Wong et al. 2000), such results confirm that acutely administered reboxetine selectively blocks the NE reuptake transporter in vivo without altering the function of the 5-HT reuptake transporter.

The potency of selective NE reuptake inhibitors or dual NE/5-HT reuptake inhibitors to suppress the firing activity of LC NE neurons by $50 \%$ (ED 50 value) correlate well with the dose required to produce a maximal prolongation of the $\mathrm{RT}_{50}$ value for NE application on $\mathrm{CA}_{3}$ pyramidal neuron firing. When comparing such $\mathrm{ED}_{50}$ and $\mathrm{RT}_{50}$ values for reboxetine (Szabo and Blier 2001) to those previously obtained with desipramine (Béique et al. 1998; Lacroix et al. 1991), a discrepancy between the potency of these two selective NE reuptake inhibitors is apparent in the hippocampus as compared to the LC. The $\mathrm{ED}_{50}$ value to suppress the firing activity of LC NE neurons for desipramine $(0.24 \pm 0.01 \mathrm{mg} / \mathrm{kg}$; Béique et al. 1998) is half that reported for reboxetine $(0.48 \pm 0.01 \mathrm{mg} / \mathrm{kg}$; Szabo and Blier 2001), whereas the effect of reboxetine to prolong the $\mathrm{RT}_{50}$ value to NE applications on $\mathrm{CA}_{3}$ pyramidal neuron firing was three times greater than that of DMI: it reached a plateau at a cumulative dose of only $2 \mathrm{mg} / \mathrm{kg}$ (Figure 2) while that of desipramine produced a maximal effect after $6 \mathrm{mg} /$ $\mathrm{kg}$ (Lacroix et al. 1991). In addition, reboxetine and duloxetine (a dual NE/5-HT reuptake inhibitor) possess nearly identical $\mathrm{ED}_{50}$ values on LC firing suppression, but reboxetine is five times more potent in prolonging the $\mathrm{RT}_{50}$ value to applications of $\mathrm{NE}$ on $\mathrm{CA}_{3}$ pyramidal neurons as compared to duloxetine (Figure 2; Kasamo et al. 1996). These results indicate that reboxetine ap-

\section{A. Control}

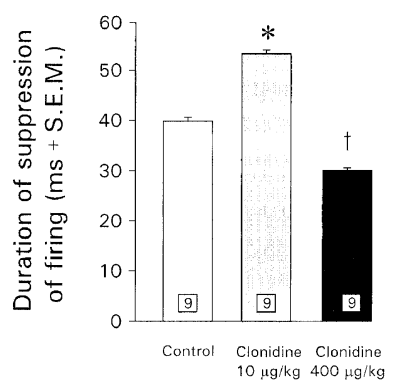

B. Reboxetine $X 21$ Days

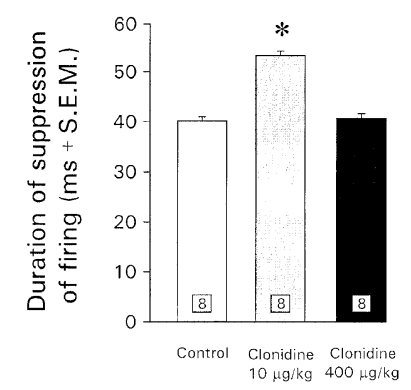

Figure 7. Histograms representing the effect of systemic injections of clonidine on the efficacy of the electrical stimulations of the ascending 5-HT pathway in suppressing the firing activity of dorsal hippocampus $\mathrm{CA}_{3}$ pyramidal neurons in control and reboxetine-treated rats. "Corresponds to an enhancement and ${ }^{+}$to a decrease as compared to controls at a $p<.001$ significance level using a 1-way ANOVA with Tukey test.

pears to be more potent on the NE reuptake process in the hippocampus than in the LC. The exact basis for this difference remains to be elucidated.

The sensitivity of postsynaptic $\alpha_{2}$-adrenergicic and $5-\mathrm{HT}_{1 \mathrm{~A}}$ receptors was not altered in the hippocampus after long-term reboxetine administration, as indicated by the number of spikes suppressed from microiontophoretic applications of $\mathrm{NE}$ and 5-HT on $\mathrm{CA}_{3}$ pyramidal neuron firing being similar (Figure 4). In contrast, it had been reported that $5-\mathrm{HT}_{1 \mathrm{~A}}$ receptors become supersensitive in postsynaptic structures to prolonged TCA treatment (de Montigny and Aghajanian 1978; Menkes et al. 1980; Wang and Aghajanian 1980). Also, TCA drugs had been shown to alter adrenoceptor function, particularly to sensitize $\alpha_{1}$-adrenoceptor in the facial motor nucleus and the lateral geniculate body and $\alpha_{2}-$ adrenoceptors in the amygdala after long-term treatment (Wang and Aghajanian 1980; Menkes et al. 1980; Menkes and Aghajanian 1981; Freedman and Aghajanian 1985). Prior to the advent of reboxetine, the lack of selective NE reuptake blocking drugs used clinically without a TCA moiety made it impossible to rule out structural versus NE components of such drugs in delineating the clinical impact of these properties. The 


\section{A. Control}

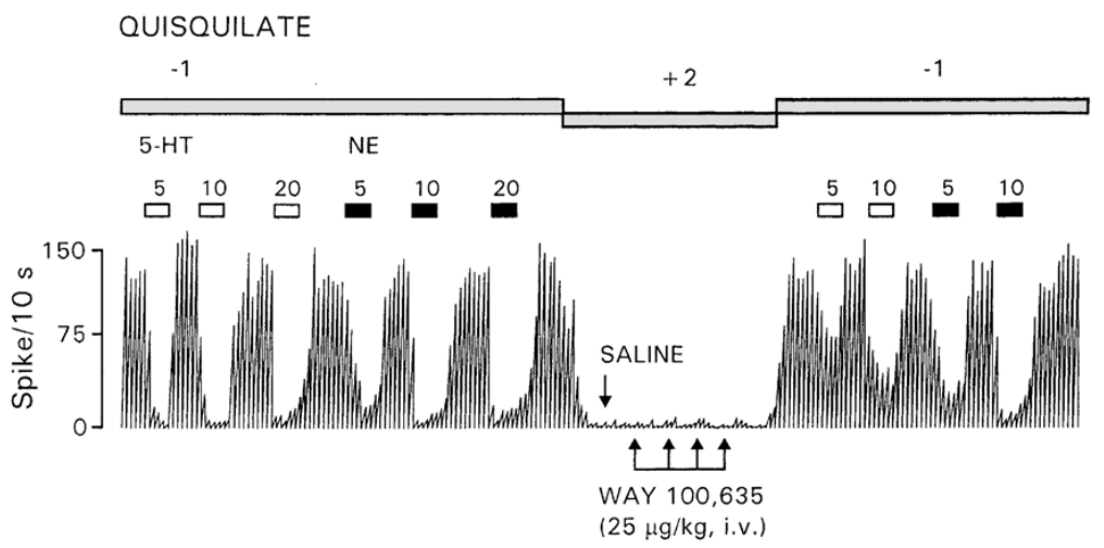

\section{B. Reboxetine X 21 days}

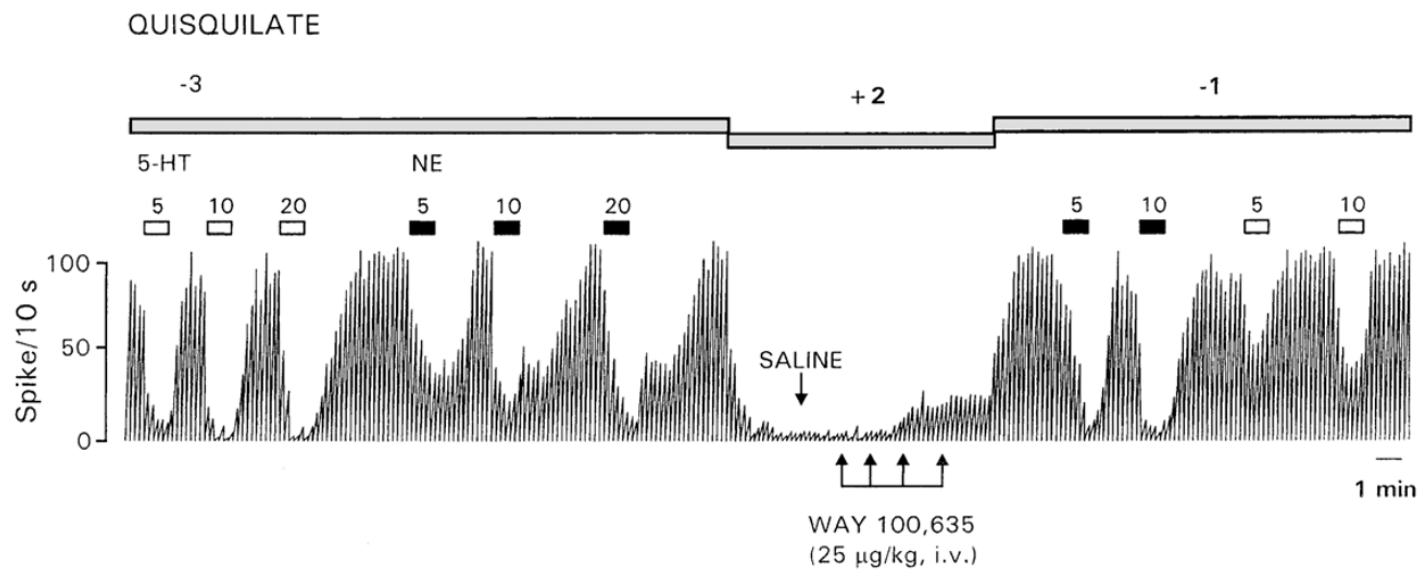

Figure 8. Integrated firing rate histogram of a dorsal hippocampus $\mathrm{CA}_{3}$ pyramidal neuron, showing its responsiveness to microiontophoretic application of 5-HT before and after the intravenous injection of WAY 100,635 (25 $\mu \mathrm{g} / \mathrm{kg} \times 4)$ in a control (Panel A) and 21-day reboxetine $(2.5 \mathrm{mg} / \mathrm{kg} /$ day) treated rat (Panel B). Horizontal bars indicate the duration of the applications (current given in $\mathrm{nA}$ ). Note the altered effectiveness of 5-HT to suppress firing activity after administration of WAY 100,635 $(100 \mu \mathrm{g} / \mathrm{kg})$ in both histograms. Although the $\mathrm{RT}_{50}$ values to NE after WAY 100,635 in 21-day reboxetine rats are reduced, two other rats had slightly prolonged $\mathrm{RT}_{50}$ values.

present results on reboxetine are thus similar to those reported by Lacroix et al. (1991), indicating that postsynaptic $\alpha_{2}$-adrenoceptors remained normosensitive in the hippocampus after long-term desipramine (10 $\mathrm{mg} / \mathrm{kg} /$ day) treatment, but stand in opposition to an increased 5- $\mathrm{HT}_{1 \mathrm{~A}}$ receptors sensitivity (de Montigny and Aghajanian 1978). In contrast, both reboxetine and desipramine have been shown to reduce the sensitivity of $5-\mathrm{HT}_{1 \mathrm{~A}}$ receptors that control the firing activity of rat LC neurons after long-term treatment (Szabo et al. 2000; Szabo and Blier 2001). Yet, reboxetine but not desipramine attenuates the $5-\mathrm{HT}_{2 \mathrm{~A}}$-receptor mediated inhibition of LC neurons firing (Szabo and Blier 2001).
These observations therefore clearly highlight that "similar" receptor subtypes located in various areas adapt differently to sustained treatment with antidepressants. Moreover, these differences among these two NE reuptake inhibitors may be due to the presence or absence of a tricyclic structure.

Consistent with the results obtained with acute reboxetine injections, rats treated with reboxetine for 21 days also presented an increase in the $\mathrm{RT}_{50}$ value to $\mathrm{NE}$ application (Figure 5, Panel A). However, in contrast to results obtained with 5-HT in the acute reboxetine experiments, long-term reboxetine treatment also increased the $\mathrm{RT}_{50}$ value for 5-HT (Figure 5, Panel B). This 


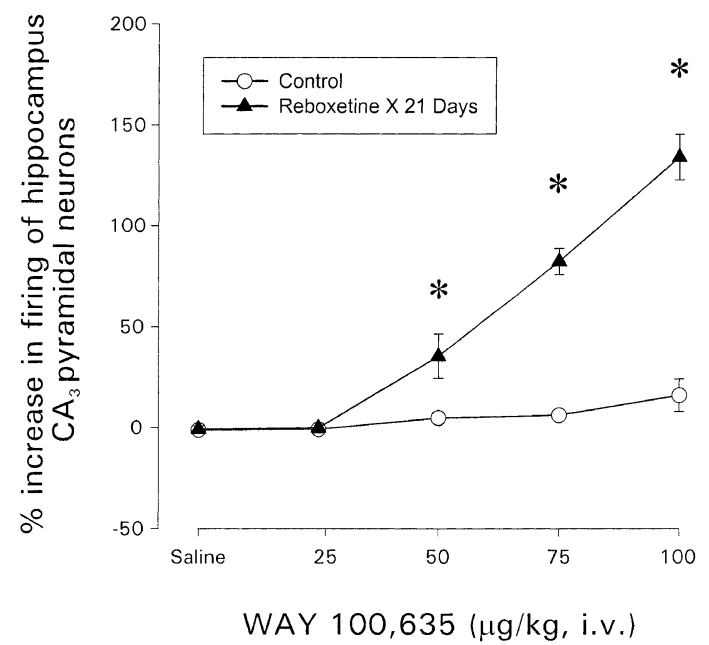

Figure 9. Effects of the intravenous injection of WAY $100,635(25 \mu \mathrm{g} / \mathrm{kg} \times 4)$ on the percent increase in the firing activity of dorsal hippocampus $\mathrm{CA}_{3}$ pyramidal neurons in controls and 21 -day reboxetine-treated rats. ${ }^{*} p<.001$ when compared to controls and each other using 1-way repeated measures ANOVA and Tukey test.

slight increase in the $\mathrm{RT}_{50}$ value observed with 5-HT after prolonged administration does not detract from reboxetine being an effective NE reuptake blocker after acute and long-term administration, but it provides evidence that this agent may produce an alteration in 5-HT transporter activity (Figure 5, Panel B). In this regard, studies have shown that NE and 5-HT transporters are both regulated by protein kinase C (Miller and Hoffman 1994; Qian et al. 1997; Apparsundaram et al. 1998). Consequently, this small inhibitory action of reboxetine on 5-HT reuptake actually may result more from intracellular events than from a direct physical inhibitory interaction of reboxetine with the 5-HT reuptake binding sites. This alteration in 5-HT reuptake function may be germane to the observation of a small but significant NE reuptake inhibition produced after a sustained SSRI treatment with paroxetine (Owens et al. 2000). The functional significance of these phenomena, given their small magnitude, are not known and must be put into perspective when considering the impact of these selective agents on antidepressant drug efficacy.

The sensitivity of somatodendritic $\alpha_{2}$-adrenergic autoreceptors which control the firing activity of LC NE neurons do not desensitize after a 21-day reboxetine administration in control rats, therefore explaining their sustained attenuation of firing activity (Szabo and Blier 2001). Similarly, the terminal $\alpha_{2}$-adrenergic autoreceptors mediating the release of NE in the hippocampus, remained normosensitive in 21-day reboxetine-treated rats (Figure 7). These results are fully consistent with the reports showing that the effect of clonidine on NE dialysates is unaltered in 14-day reboxetine-treated rats in the hippocampus, but attenuated in the frontal cortex
(Invernizzi et al. 2001). However, drugs which increase the synaptic availability of NE desensitize $\alpha_{2}$-adrenergic heteroreceptors located on 5-HT terminals in the hippocampus and may account for an increase in synaptic 5-HT availability in the same structure (Mongeau et al. 1994a; Yoshioka et al. 1995) and other postsynaptic structures (Blier and Bouchard 1994). It was thus decided to assess whether reboxetine desensitized the terminal $\alpha_{2}$-adrenergic heteroreceptors located on 5-HT terminals, as previously reported with desipramine (Mongeau et al. 1993; Yoshioka et al. 1995). Reboxetine did desensitize terminal $\alpha_{2}$-adrenergic heteroreceptors as determined by the attenuated response to the high dose of clonidine $(400 \mu \mathrm{g} / \mathrm{kg})$ on hippocampus neurons (Figure 7, Panel B). This effect is likely mediated by an increased availability of NE because the MAOI befloxatone could no longer desensitize this heteroreceptor in NE lesioned rats (Mongeau et al. 1994a).

The amount of 5-HT being released per impulse reaching 5-HT terminals was not altered in 21-day reboxetine as compared to saline-treated rats: there was no change in the efficacy of 5-HT fiber stimulation on hippocampus neuron firing as demonstrated in Figure 6 . This paradigm assesses terminal $5-\mathrm{HT}_{1 \mathrm{~B}}$ autoreceptor sensitivity located on 5-HT neurons controlling 5-HT release. A change in sensitivity of this receptor subtype is usually indicative of antidepressants that potently block the reuptake of 5-HT (Mongeau et al. 1994a), such as citalopram (Chaput et al. 1991), fluvoxamine (Dong et al. 1999), fluoxetine (Blier et al. 1988), paroxetine (Chaput et al. 1991), and venlafaxine (Béique et al. 2000). Clearly then, reboxetine does not belong to that category of antidepressant agents.

It is interesting that a drug like reboxetine which increases the synaptic availability of NE can also increase that of 5-HT in the hippocampus. As compared to controls, the $140 \%$ increase in $\mathrm{CA}_{3}$ pyramidal neuron firing in response to i.v. administration of the selective $5-\mathrm{HT}_{1 \mathrm{~A}}$ receptor antagonist WAY 100,635 (Figure 8, Panel B, and Figure 9), is well within the range of that produced with other antidepressant treatments (Béique et al. 2000; Rueter et al. 1998; Haddjeri et al. 1998), with lithium addition (Haddjeri et al. 2000) and even to a greater extent with the combination of mirtazapine and paroxetine than either drug alone (Besson et al. 2000). It is interesting to note that the latter strategies are endowed with a greater antidepressant efficacy (Rouillon and Gorwood 1998; Debonnel et al. 2000). These observations therefore provide considerable face validity for the use of the hippocampus as a brain structure relevant to antidepressant drug action. However, since the effectiveness of the stimulation of the afferent 5-HT pathway to the hippocampus is unaltered in 21-day reboxetine-treated rats, a small inhibition of 5-HT reuptake, combined with decreased $\alpha_{2}$-adrenergic heteroreceptors sensitivity on 5-HT terminals (Figure 7, 
Panel B), may then be postulated to account for the increased tonic activation of $5-\mathrm{HT}_{1 \mathrm{~A}}$ receptors in the hippocampus of these animals.

In conclusion, it has been shown that NE availability in the hippocampus is enhanced by reboxetine treatment via blockade of the NE transporter (Sacchetti et al. 1999). Since both the acute and long-term administration of reboxetine produced the same degree of enhancement of NE in the extracellular milieu in the same experiments in the hippocampus, the relationship between the delayed clinical response to reboxetine with respect to hippocampal function is not clear. However, the hippocampus is endowed with excitatory $\beta$-adrenoceptors, inhibitory $\alpha_{1}$-adrenergic and $\alpha_{2}$-adrenergic receptors (Curet and de Montigny 1988a,b; Lacroix et al. 1991). Thus, it appears that a delayed desensitization of $\beta$-adrenoceptors, which is common to most antidepressant treatments, including desipramine, also occurs with reboxetine (Riva et al. 1989; Lacroix et al. 1991). This would lead to an overall increased inhibitory action of the treatment on the firing of pyramidal neurons mediated by a decreased function of excitatory $\beta$-adrenoceptors and an increased activation of normosensitive $\alpha$-adrenergic and $5-\mathrm{HT}_{1 \mathrm{~A}}$ receptors. The increase in transmission at $5-\mathrm{HT}_{1 \mathrm{~A}}$ receptors in the hippocampus, also common to all antidepressant treatments, occurs for reboxetine, although not via their sensitization as is the case for TCA drugs, but rather via an increase in 5-HT availability. The latter effect of sustained reboxetine administration on the 5-HT system with respect to the antidepressant response is currently not known. A dietary tryptophan depletion in patients responding to reboxetine treatment for major depression could shed light on this issue.

\section{ACKNOWLEDGMENTS}

This work was supported in part by Pharmacia \& Upjohn, a Medical Research Government of Canada (MRC) Grant (MT11410 to P.B.), a MRC doctoral award (MRC-1554 to S.T.S.), a Fonds pour la Formation de Chercheurs et L'Aide à la recherche-Fonds de al Recherche en Santé du Québec (FRSQ-FCARSanté-68803 to S.T.S.), and by salary support from the University of Florida to P.B. and S.T.S.

\section{REFERENCES}

Apparsundaram S, Schroeter S, Giovanetti E, Blakely RD (1998): Acute regulation of norepinephrine transport: II. PKC-modulated surface expression of human norepinephrine transporter proteins. J Pharmacol Exp Ther 287:744-751

Béïque J, Lavoie N, de Montigny C, Debonnel G (1998): Affinity of venlafaxine and various reuptake inhibitors for the serotonin and norepinephrine transporters. Eur J Pharmacol 349:129-132
Béïque J, de Montigny C, Blier P, Debonnel G (2000): Effects of sustained administration of the serotonin and norepinephrine uptake inhibitor venlafaxine: I. In vivo electrophysiological studies in the rat. Neuropharmacology 39:1800-1812

Besson A, Haddjeri N, Blier P, de Montigny C (2000): Effects of the co-administration of mirtazapine and paroxetine on serotonergic neurotransmission in the rat brain. Eur Neurophsychopharmacol 10:177-188

Blier P (2000): Serotonergic drugs and panic disorder. J Psychiatry Neurosci 3:237-238

Blier P, de Montigny C (1983): Electrophysiological investigations on the effect of repeated zimelidine administration on serotonergic neurotransmission in the rat. J Neurosci 3:1270-1278

Blier P, de Montigny C (1985): Serotonergic but not noradrenergic neurons in rat CNS adapt to long-term treatment with monoamine oxidase inhibitors. Neuroscience 16:949-955

Blier P, Chaput Y, de Montigny C (1988): Long-term 5-HT reuptake blockade but not monoamine oxidase inhibition decreases the function of terminal 5-HT autoreceptors: an electrophysiological study in the rat brain. Naunyn-Schiedeberg's Arch Pharmacol 337:246-254

Blier P, Ramdine R, Galzin AM, Langer SZ (1989): Frequency-dependence of serotonin autoreceptor but not alpha 2-adrenoceptor $[3 \mathrm{H}]$-serotonin release in rat hypothalamic slices. Naunyn-Schmiedeberg's Arch Pharmacol 339:60-64

Blier P, Bouchard C (1994): Modulation of 5-HT release in the guinea-pig brain following long-term administration of antidepressant drugs. Br J Pharmacol 113:485495

Blier P, de Montigny C (1999): Serotonin and drug-induced therapeutic responses in major depression, obsessivecompulsive disorder and panic disorders. Neuropsychopharmacology 21 (suppl 2): 91S-98S

Bremner JD, Narayan M, Anderson ER, Staib LH, Miller HL, Charney DS (2000): Hippocampal volume reduction in major depression. Am J Psychiatry 157:115-118

Brunel S, de Montigny C (1987): Diurnal rhythms in the responsiveness of hippocampal pyramidal neurons to serotonin, norepinephrine, gamma-aminobutyric acid and acetylcholine. Brain Res Bull 18:205-212

Chaput Y, de Montigny C, Blier P (1986): Effects of a selective 5-HT reuptake blocker, citalopram, on the sensitivity of 5-HT autoreceptors: Electrophysiological studies in the rat. Naunyn-Schmiedeberg's Arch Pharmacol 33:342-349

Chaput Y, de Montigny C (1988): Effects of the 5-hydroxytryptamine receptor antagonist, BMY 7378, on 5-hydroxytryptamine neurotransmission: electrophysiological studies in the rat central nervous system. J Pharmacol Exp Ther 246:359-370

Chaput Y, de Montigny C, Blier P (1991): Presysnaptic and postsynaptic modifications of the serotonin system by long-term administration of antidepressant treatments. An in vivo electrophysiologic study in the rat. Neuropsychopharmacology 5:219-229

Curet O, de Montigny C (1988a): Electrophysiological characterization of adrenoceptors in the rat dorsal hippocampus. 
I. Receptors mediating the effect of microiontophoretically applied norepinephrine. Brain Res 475:35-46

Curet O, de Montigny C (1988b): Electrophysiological characterization of adrenoceptors in the rat dorsal hippocampus. II. Receptors mediating the effect of synaptically released norepinephrine. Brain Res 475:47-57

Curet O, de Montigny C, Blier P (1992): Effect of desipramine and amphetamine on noradrenergic neurotransmission: electrophysiological studies in the rat brain. Eur J Pharmacol 221:59-70

Debonnel G, Gobbi G, Turcotte J, Boucher N, Hébert C, de Montigny C, Blier P (2000): Comparative study of the therapeutic effects of $\alpha_{2}$-adrenergic antagonism, serotonin reuptake inhibition and their combination in major depression. Int J Neuropsychopharm 3 (suppl 1):S37

de Montigny C, Aghajanian GK (1978): Tricyclic antidepressants: Long-term treatment increases responsivity of rat forebrain neurons to serotonin. Science 202:1303-1306

de Montigny C, Wang RY, Reader TA, Aghajanian GK (1980): Monoaminergic denervation of the rat hippocampus: microiontophoretic studies on pre- and postsynaptic supersensitivity to norepinephrine and serotonin. Brain Res 200:363-376

Dong J, de Montigny C, Blier P (1999): Assessment of the serotonergic reuptake blocking property of YM992: electrophysiological studies in the rat hippocampus and dorsal raphe. Synapse 34:277-289

Fletcher A, Forster EA, Bill DJ, Brown G, Cliffe IA, Hartley JE, Jones DE, McLenachan A, Stanhope KJ, Critchley DJ, Childs KJ, Middlefell VC, Lanfumey L, Corradetti R, Laporte Am, Gozlan H, Hamon M, Dourish CT (1996): Electrophysiological, biochemical, neurohormonal and behavioural studies with WAY-100,635, a potent, selective and silent $5-\mathrm{HT}_{1 \mathrm{~A}}$ receptor antagonist. Behav Brain Res 73:337-353

Freedman JE, Aghajanian GK (1985): Opiate and alpha 2-adrenoceptor response of rat amygdaloid neurons: colocalization and interactions during withdrawal. J Neurosci 5:3016-3024

Göthert M, Huth H (1980): Alpha-adrenoceptor-mediated modulation 5-hydroxytryptamine release from rat brain cortex slices. Naunyn-Schmiedeberg's Arch Pharmacol 313:21-26

Haddjeri N, Szabo ST, de Montigny C, Blier P (2000): Increased tonic activation of rat forebrain $5-\mathrm{HT}_{1 \mathrm{~A}}$ receptors by lithium addition to antidepressant treatments. Neuropsychopharmacology 22:346-356

Haddjeri N, Blier P, de Montigny C (1998): Long-term antidepressant treatments result in a tonic activation of forebrain 5- $\mathrm{HT}_{1 \mathrm{~A}}$ receptors. J Neurosci 18:10150-10156

Heninger GR, Charney DS, Sternberg DE (1984): Serotonergic function in depression. Prolactin response to intravenous tryptophan in depressed patients and healthy subjects. Arch Gen Psychiat 41:398-402

Hensler JG, Ferry RC, Labow DM, Kovachich GB, Fazer A (1994): Quantitative autoradiography of the serotonin transporter to assess the distribution of serotonergic projections from the dorsal raphe. Synapse 17:1-15

Invernizzi RW, Parini S, Sacchetti G, Fracasso C, Caccia S, Annoni K, Samanin R (2001): Chronic treatment with reboxetine by osmotic pumps facilitates its effect on extracellular noradrenaline and may desensitize alpha(2)adrenoceptors in the prefrontal cortex. 132:183-188
Kasamo K, Blier P, de Montigny C (1996): Blockade of the serotonin and norepinephrine uptake processes by duloxetine: in vitro and in vivo studies in the rat brain. J Pharmacol Exp Ther 277:278-286

Kandel ER, Spencer WA (1961): Electrophysiology of hippocampal neurons. II. After potentials and repetitive firing. J Neurophysiol 24:243-259

Lacroix D, Blier P, Curet O, de Montigny C (1991): Effects of long-term desipramine administration on noradrenergic neurotransmission: electrophysiological studies in the rat brain. J Pharmacol Exp Ther 257:1081-1090

Malberg JE, Eisch AJ, Nestler EJ, Duman RS (2000): Chronic antidepressant treatment increases neurogenesis in adult rat hippocampus. J Neurosci 15:9104-9110

Mateo Y, Pineda J, Meana JJ (1998): Somatodendritic alpha2adrenoceptors in the locus coeruleus are involved in the in vivo modulation of cortical noradrenaline release by the antidepressant desipramine. J Neurochem 71:790798

Menkes DB, Aghajanian GK (1981): alpha 1-Adrenoceptormediated responses in the lateral geniculate nucleus are enhanced by chronic antidepressent treatment. Eur J Pharmacol 74:27-35

Menkes DB, Aghajanian GK, McCall RB (1980): Chronic antidepressant treatment enhances alpha-adrenergic and serotonergic responses in the facial nucleus. Life Sci 27:45-55

Miller KJ, Hoffman BJ (1994): Adenosine A3 receptors regulate serotonin transport via nitric oxide and cGMP. J Biol Chem 269:27351-27356

Mongeau P, Blier P, de Montigny C (1993): In vivo electrophysiological evidence for tonic activation by endogenous noradrenaline on $\alpha_{2}$-adrenoreceptors on 5-hydroxytryptamine terminals in the rat hippocampus. Naunyn-Schmiedeberg's Arch Pharmacol 347:266-272

Mongeau R, de Montigny C, Blier P (1994a): Electrophysiological evidence for desensitization of $\alpha_{2}$-adrenoceptors on serotonin terminals following long-term treatment with drugs increasing norepinephrine synaptic concentration. Neuropsychopharmacology 10:41-51

Mongeau R, de Montigny C, Blier P (1994b): Effect of longterm alpha- 2 adrenergic antagonists and electroconvulsive shock treatments on the alpha- 2 adrenoceptors modulating serotonin neurotransmission. J Pharmacol Exp Ther 256:269-279

Moret C, Briley M (1994): Effect of milnacipran and desipramine on noradrenergic alpha 2-autoreceptor sensitivity. Prog Neuropsychopharmaco Biol Psychiat 18:1063-1072

Owens MJ, Knight DL, Nemeroff CB (2000): Paroxetine binding to the rat norepinephrine transporter in vivo. Biol Psychiatry 47:842-845

Piñeyro G, Blier P, Dennis T, de Montigny C (1994): Desensitization of the neuronal 5-HT carrier following its longterm blockade. J Neurosci 14:3036-3047

Qian Y, Galli A, Ramamoorthy S, Risso S, DeFelice LJ, Blakely RD (1997): Protein kinase C activation regulates human serotonin human serotonin transporters in HEK-293 cells via altered cell surface expression. J Neurosci 17:45-57

Ranck JB (1975): Behavioral correlates and firing repertories 
of neurons in the dorsal hippocampus formation of unrestrained rats. In Isacson I and Robert L (eds), The Hippocampus. New York, Plenum, pp 207-224

Riva M, Brunello N, Rovescalli AC, Galimberti R, Carfagna N, Carminati P, Pozzi O, Ricciardi S, Roncucci R (1989): Effect of reboxetine, a new antidepressant drug, on the central noradrenergic system: Behavioural and biochemical studies. J Drug Dev 1:243-253

Rouillon F, Gorwood P (1998): The use of lithium to augment antidepressant medication. J Clin Psychiat 59 (suppl 5):32-39

Rueter LE, Kasamo K, de Montigny C, Blier P (1998): Effect of long-term administration of duloxetine on the function of serotonin and noradrenaline terminals in the rat brain. Naunyn-Schmiedeberg's Arch Pharmacol 375: 600-610

Sacchetti G, Bernini M, Bianchetti A, Parini S, Invernizzi RW, Samanin R (1999): Studies on the acute and chronic effect of reboxetine on extracellular noradrenaline and other monoamines in the rat brain. Brit J Pharmacol 128: 1332-1338

Sheline YI, Sanghavi M, Mintun MA, Gado MH (1999): Depression duration but not age predicts hippocampal volume loss in medically healthy women with recurrent major depression. J Neurosci 15:5034-5043

Szabo ST, Blier P (2000a): Effect of combined 5-HT reuptake inhibition and 5- $\mathrm{HT}_{2 \mathrm{~A}}$ antagonism on the firing activity of NE neurons. Soc Neurosci 26:1928

Szabo ST, Blier P (2001): Effect of the selective noradrenergic reuptake inhibitor reboxetine on the firing activity of noradrenaline and serotonin neurons. Eur J Neurosci 13:2077-87

Szabo ST, de Montigny C, Blier P (1999): Modulation of noradrenergic neuronal firing by selective serotonin reuptake blockers. Brit J Pharm 126:568-571

Szabo ST, de Montigny C, Blier P (2000): Progressive attenuation of the firing of locus coeruleus noradrenergic neurons by sustained administration of selective serotonin reuptake inhibitors. Int J Neuropsychopharm 3:1-11

Vandermaelen CP, Aghajanian GK (1983): Electrophysiological and pharmacological characterization of serotonergic dorsal raphe neurons recorded extracellularly and intracellularly in rat brain slices. Brain Res 289:109-119

Yoshioka M, Matsumoto M, Numazawa R, Togashi H, Smith CB, Saito H (1995): Changes in the regulation of 5-hydroxtryptamine release by alpha2-adrenoceptors in the rat hippocampus after long-term desipramine treatment. Eur J Pharmacol 294:565-570

Wang RY, Aghajanian GK (1980): Enhanced sensitivity of amygdaloid neurons to serotonin and norepinephrine antidepressant treatment. Commun Psychopharmacol 4:83-90

Wong Eh, Sonders MS, Amara SG, Tinholt PM, Piercey MF, Hoffman WP, Hyslop DK, Franklin S, Porsolt RD, Bonsignori A, Carfagna N, McArthur RA (2000): Reboxetine: a pharmacologically potent, selective, and specific norepinephrine reuptake inhibitor. Biol Psychiat 47: 818-829 